\title{
Self Me: Interpretation of Self-Injury in the Context of Healing
}

\author{
Hana Medita ${ }^{\text {a,1,* }}$ Nazima Rangwala Kalita ${ }^{\text {b,2, }}$ \\ ${ }^{a}$ Pascasarjana Institut Seni Indonesia Surakarta, Indonesia \\ ${ }^{\mathrm{b}}$ Association for Scientific Computing Electronics and Engineering (ASCEE), ASCEE Visual and Performing Arts Society, India Section, India \\ ${ }^{1}$ hanamedita55@gmail.com *22 nazkalita@yahoo.co.in \\ * Corresponding Author
}

published 2021-10-19

\begin{abstract}
The work Self Me focuses on the topic of self-injury, which is influenced by a number of factors, including bullying and mild to severe stress. The purpose of this study is to process the expression of pain from a self-injury into a dance work. Self $\mathrm{Me}$ is in the form of research-based work using asymmetrically arranged wood and ropes as a medium for symbolic expression. The dancers involved use one dancer who represents several backgrounds. There are five segments of Self Me's work, the first is how a person tries to accept life symptoms that can become self-injury. The second segment is the feel-good phase of self-injury. The third segment expresses comfort in solitude, the fourth is about being stuck with problems that are difficult to get out of and the fifth expresses various emotions asynchronous feelings and thoughts. This research revealed self-concept findings, meaning that difficulties may be overcome when we confront ourselves. All issues and answers that decide are self, thus self means self and I means myself.
\end{abstract}

\section{KEYWORDS}

Self-injury;

Mental balance; Self me

This is an open access article under the CC-BY-SA license

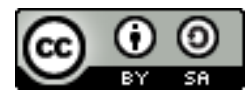

\section{Introduction}

The development of modernization nowadays affects human needs. The advanced age always demands to think and have to work fast which causes mental health symptoms. Some of the symptoms include bipolar disorder, anxiety disorder (GAD), depression, and self injury. Bipolar is a mental disorder that attacks the brain and results in disturbed mood, energy, activity and work. Symptoms of bipolar disorder can result in damaged social relationships and lead to suicide. The factors that cause bipolar symptoms are genetics, brain structure and function (Douglas et al. 2016). Anxiety disorder or GAD (Generalized Anxiety Disorder) is fear or anxiety about social situations both before and after or in these situations. Anxiety or anxiety is an unpleasant emotional state characterized by fear and unwanted physical symptoms. Often makes individuals feel inferior, irritable, and detrimental to themselves and others (Yusuf, Kusniyati, and Nuramelia 2016). Self injury is a widespread phenomenon, although many people do not realize and know the disorder or symptom. According to WHO, self-injury or self-harm is an act that is not fatal because someone deliberately initiates behavior without intervention from others. This behavior causes pain in oneself which results in physical changes as an expression of the unpleasant feelings that are felt. Bipolar and anxiety disorders are characterized by direct mood swings in terms of the explanation. Self injury has a tendency towards itself to injure. Self injury can be in bipolar disorder because many phenomena occur when someone who is bipolar often hurts himself. A person who has a history of bipolar disorder usually passes these traits down to hereditary children. In contrast to self-injury that occurs because of the environment and level of awareness to control oneself in difficult situations. Self injury is the act of injuring oneself intentionally by oneself. This action is carried out not with the intention of committing suicide, but as a way to vent painful emotions felt by individuals, because individuals are unable to express their negative emotions in words (Hamza and Willoughby 2018; Kalita 2019).

In addition, self-injury is a form of behavior that is done to deal with pain emotionally. Self injury is also a form of self-defense mechanism that a person uses to deal with emotional pain, selfemptiness, loneliness, loss, and satisfying the desire to punish oneself by causing injury to the body (Rusiana and Keliat 2021). Various possible backgrounds arise, including social problems, especially victims of bullying, family and friend conflicts and experiencing an identity crisis. Psychological trauma, victims of emotional, physical, and sexual abuse leave a person feeling empty and inferior. 
Mental disorders such as mood disorders, depression, eating disorders, and personality disorders. Someone who experiences self-injury has different characteristics for each individual. They do not show to many people but rather vent out alone in the dark. Some experts classify self-injury into three forms, namely mild, moderate, and serious. Mild self-injury includes picking dry lips, biting nails, dieting and squeezing pimples and blackheads. Moderate self-injury, namely scratching, scratching the body until wounds arise, smoking, and consuming excess alcohol. Serious self-injury includes scratching sharp objects on the body, burning certain bodies, banging the head and body against the wall (Augarde and Rydon-Grange 2022).

The work entitled Self Me focuses on the phenomenon of Self injury which is caused by several causes that influence it, especially bullying and light and severe stress. This is interesting because from a psychological perspective, a person can be two different characters and influence each other. As awareness of the factors or symptoms of self-injury from an early age, so that we can behave towards ourselves and the environment. Starting from the psychological trauma experienced by the employee, leading to self-injury. This greatly affects changes in psychology and mental balance. The mental balance is divided into four dimensions, namely the physical dimension, mental dimension, social dimension, and spiritual dimension (Akinlosotu et al. 2021). Indirectly, when one dimension is disturbed it will result in an imbalance in human psychology. That's why this work was created starting from the worker's body experience and an expression of the pain he feels. Self Me is an interpretation of the deep pain of a self-injury that results from the emotional aspects that occur. Self means self and Me means I, from these two words expressing that only oneself can control their own emotions. The search and meaning mentioned above, underlie the creation of a work by processing the expression of the pain of a self-injury. The research used research based on the worker's body memorial, interviews and several phenomena about self-injury.

\section{Method}

The process of creating Self Me works using several methods. The first method used was observation, then another method was obtained through one of the books, namely Artistic Creations written by Dharsono, namely exploration and experimentation, contemplation, and formation (Dharsono Sony Kartika 2016). The method of observation is carried out by the writer by looking for data or written or oral sources for the vocabulary of the work and interviews with the sources. In addition to interviews, the employee is also looking for data using the google form. The form was distributed and responded to by 37 people from various regions. After the interview, the next steps were exploration and experimentation. This step is to find and design the worker's body memorial. The exploration was carried out by inviting several sources to express their emotions and artistic experiments. Next is the process of contemplation as a description of the inner worker's search for symbols. Contemplation is done to look for or find symbols that characterize the artistic creative process. The last method is reflection which composes everything into a structure of the work and produces the desired dynamics and atmosphere.

\section{Results and Discussion}

\subsection{Visualization of the work of Self Me}

Self Me is a work inspired by the experience of the author about self injury. The title Self Me means that only oneself can control emotional control. Self means self and Me means me, the two words are combined and represent what you want to convey in your work. Self Me is an audiovisual form with a virtual performance concept. Using editing techniques in the production of his video. This work uses several symbolic properties to interpret the feelings expressed. The wood and rope are chosen as symbols in this work. Apart from that, several scenes were also presented to support this work. Self Me's work is divided into five segments. The first segment describes the many factors that can lead to self injury. Using asymmetrically arranged wood as a medium reveals problems affecting self injury. Wood is also defined as a sharp object that can hurt or injure the body. The gap is passed by the dancer by utilizing the balance and strength of the body. The balance here reveals the selfcontrol that exists in humans. The poses that appear are the results of research on self-injury by several informants. In addition, the poses are also in accordance with the worker's body memory. This segment is indicated by the change of white to red. The purpose of this change is a very long time in this phase. Starting from bright red to red indicates a long time of experiencing problems. The second 
segment of Self Me shows a self-injury experiencing a comfortable phase in a problem at hand. This comfort does not last long because it feels something bad to feel. This segment is visualized with a projector lamp that shines the dancers. The dancer is in the artistic center and moves on a square of the spotlight. Addition of sand, use of lighting, and a projector focused on one angle and atmosphere. The third segment is a depiction of an atmosphere of solitude. Using room visuals with multiple activities in one scene that uses editing interference. Although he can do any activity by himself, he can only feel the solitude within him. The choice of location in the room is an apt description of this own atmosphere. The room is a place to vent or do something without any distraction. The fourth segment of depiction is caught up in the problem at hand using ropes. The rope that is presented as a symbol of being entangled in a self-injury person to the problem he is really facing. The difficulty of controlling yourself makes this problem a threat. The fifth segment expresses emotions with facial visuals. Things that have been hidden and cannot be expressed are brought up into facial emotions. The pressure, distraction and discomfort facing the problems presented in this segment. The expressions shown were sad, angry, crying, hitting oneself, and some expressions like wanting to talk but could only bury them. The combination of expressions is arranged into a series and packed with glitch effects. A glitch is an effect that is used in the form of a computer glitch, such as an error that becomes an error or it can be called a corrupted image. Glitch is an effect that is used in the form of computer effects, such as an error that can be called a corrupt image (Pan et al. 2019). The glitch effect is used to describe asynchronous thoughts and feelings. After the fifth segment, a relaxation music is displayed which is intended to neutralize the previous image. Served in three minutes to relax the human brain. Using alpha waves in music is indeed for calming. The five-segmented scene ends in self-control. Returning to self-injury, which is self-injurious behavior without the will to commit suicide. Another meaning that self-harm also has three forms, namely mild, moderate, and severe. Stress levels really affect a person to hurt himself due to his lack of emotional regulation.

The mental, physical, social, and spiritual balance is also associated with self injury. This balance becomes unbalanced when a person is mentally destroyed due to influencing factors. Situations like this that can lead to self-injury, everyone has a different degree of self-injury experience. Healing from one another also differs depending on the level of awareness and self-control. When the mental is out of balance, it will greatly affect one's physicality. In addition, the social environment also influences to stay away, because mental imbalance causes disturbances such as this self injury. Self-control or self-control is very necessary in handling self-judgment. Self control itself is a behavior that is able to guide one's own behavior or the ability to cope with the condition of taking action without thinking about the consequences (Tehrani and Yamini 2020). Because with self-control, someone knows their emotional limits and reduces them as quickly as possible so that unwanted things do not happen. In addition, self love is also very important in exploring yourself as a human who must accept the reality that occurs. Self love here can mean appreciating and respecting and understanding oneself. We can act as is and even be realistic about the advantages and disadvantages of being comfortable yourself (O'donovan 2006). Self love does not mean having to pamper yourself to a salon or something like that but rather forgiving mistakes, being selfish, accepting the reality that happens both mentally, physically, and others. By knowing yourself or loving yourself and self-control, a person will have minimal interference that can complicate his life. Self control and self love are very important in this life and also as a way to avoid or heal self-injury from yourself.

\subsection{The concept used in the use of self-Me works}

According to Dharsono, there are several concepts of work, including Revitalization, which means that traditional studies seek alternative preservation by bringing back cultural heritage from the past. Reinterpretation, utilizing story themes and traditional idioms that structurally refer to modern techniques. Symbolic abstraction, modern art that utilizes traditional idioms as a basic element of compilation and contextually experiences a reduction in interpreting forms symbolically (Dharsono Sony Kartika 2016). The author agrees with Dharsono's statement that this work leads to symbolic abstraction. According to the author, this work is abstracted through people's interpretations with the virtual forms presented. As a basic element the author chooses to search for public research. That way you can find other alternatives for yourself that are symbolized according to the interpretation of the abstraction. The initial process carried out by the author in developing this work was observation by conducting interviews. Interviews were conducted with several self-injury sufferers and the general public. The results of the interviews conducted, there were two people who experienced severe level 
of self injury. Both of these people were able to get through the toughest phase of self injury that happened to him. What he did was squeal his body until it was bleeding and leaving a scar. In addition, other sources did not understand and only knew about self-injury in general. In addition to interviews, the workers distributed a google form which 37 respondents from various regions responded to. After that, exploration, experimentation and reflection are carried out to find the desired symbols and visuals. Exploration was carried out with several interviewees to explore their emotions. The places that are used for exploration also vary, some are in training areas, in public places, fences, lobbies, and closed rooms such as rooms. The various emotions that were raised were also different. This observation is very interesting because each person has a different way of expressing and overcoming the problems at hand. Emotions that often arise from the observations of employees are angry emotions that are sometimes difficult to express in words. Besides that, the expressions most often raised were crying, being silent, and hitting oneself. The results of the exploration are used as material for the cultivation of segments in the work. In addition, experiments with several media, namely sand, wood, stone, and rope. Experiments were carried out to find a suitable symbol of the expressed media for the work of a work that originates from the phenomenon of self injury. From the results of exploration, experiment, and observation then processed in the process of reflection. After contemplation, what is done is formation.

The formation here starts from the selection and artistic creation. Finally, in the artistic selection, the artist chooses wood that is arranged asymmetrically as a symbol of disturbance or symptoms that cause a person to become a self-injury. Asymmetry means the arrangement of techniques that are arranged abstractly randomly but still emphasizes beauty, and does not mean random irregular origin (Manurung 2019). Besides that, the wood is also painted black as a whole. Black is very synonymous with the presentation of strength and mystery, but many also think that black is a feeling of depression, a disturbance, destruction and emptiness to death (Costa et al. 2021). This is the reason for coloring wood with black paint. Wood is chosen because it is based on the nature of the wood which is strong and can injure the skin when not careful to handle the wood (Rosdiana et al. 2017). Asymmetrical arrangement means the number of factors that can affect a person regardless of the person's background. The rope is used as a symbol of entangling troubles. This results in limited space for movement and is very detrimental. In addition to wood, the craftsmen use rope as an artistic one in one segment. The use of rope is intended as a person's attachment to the problem at hand. The more you want to go out the tighter the rope will tie. Show the intricacy side of the problem and get stuck. So that it is completely locked and unable to move. Ropes are applied to both hands and the legs are stretched out.

Music is an important role in a work. The music here provides the atmosphere and expression you want it to convey. The music used in this work is atmosphere music as a support in each segment. The reason for choosing atmosphere music that is used as a support for the work is that it can make the work more lively and reinforce the expression and atmosphere. The options that appear are very diverse. The choice is to use ambience music and add sound reading of self-injury issues, incidents or events. The techniques used in the cultivation of music are soundscape processing and electronic processing. This technique is used to produce synthetic-based electronic music. Synthetic-based because it uses existing instrument sound playing and is programmed through a computer programmed. The combination of atmosphere music, ambience and reading of self-injury events using soundscape processing techniques and electronic processing makes the expression and atmosphere of Self Me's work conveyed. The last part of the work is presented relaxation music. This music aims to calm the brain that is under a lot of stress. Relaxation music is music that has alpha waves. Alpha waves in music are intended to lead the human brain to relax. In humans, there is music in which the microcosmic context of the body is divided into alpha, beta and gamma waves (Pfeifer, Fiedler, and Wittmann 2019). So that at the beginning, a visual interpretation of self-injury pain is presented with music to support the atmosphere, then it is connected to relaxation music. Relaxation music is intended as a healing of feelings that cause the tense brain to relax. After hearing the music, everyone returns to the listener, whether they feel calm, dizzy, scary and others. Basically, the human brain has different waves. Not all humans are ready to listen to relaxation music or music with alpha waves.

Dancers are important and become a focus in dance performance. Self Me works using one dancer as a link between the interpretation of ideas to the audience. One dancer represents a variety of different backgrounds. Dancers are a living tool capable of objectifying the subjectivity of the dance 
stylist concept. The determination of the number of dancers depends on the need for the concept of work (Rallis et al. 2018). The single dancer creates a unity of stimulus and response artistically. There is a symbolic interaction obtained by improvisation so as to interpret the ideas in the work of Self Me. Motion is an important thing in the show. The selection of movements in Self Me's work goes through a research process carried out by the author. The motion obtained is daily and exploration movement. Through the process of distortion and sterilization, these movements produce an interpretation of the feeling of self-injury. The balance of self-control becomes the benchmark in shaping the work. Following the artistic form used by following artistic patterns or grooves and the movement is done by processing balance. The work of Self Me is not much work, but rather expresses emotions with facial expressions. The movements that are carried out have the motivation to balance oneself, the strength of the hands when in a narrow state, and the expression of wanting to get out of a problem. The rest are facial expressions when feeling alone and even many expressions that are expressed such as anger, sadness, crying, etc. This division of motion and expression is divided into five segments and each segment addresses a different behavior. Costumes are used in a show and become a characteristic or support to play a role. This Self Me work uses several costumes for everyday wear. The costume is used one per segment. The costumes worn in one segment are different from another, because they explain different individuals and different backgrounds for each segment. Daily clothes are chosen because they show the life of a self-injury in their daily life. In addition, it shows the various backgrounds of any person who can suffer from self injury. Therefore, everyday clothes are chosen to generalize various backgrounds and do not designate one background.

\section{Conclusion}

Self injury is very common among adolescents towards adulthood and there are many symptoms that are very likely to affect a person's mental or mental health. This mental imbalance in a person ultimately causes self-injury. Some of the poses that are done are poses where as a symbol that when the psyche is disturbed you may feel comfortable or give up on the situation. The feeling of pain that is felt is the reference and symbol that is conveyed. The ideal foundation above is interpreted in works with one or single dancers. The selection of a single dancer is because in someone's problem, that person will solve the problem. Even though there are those who help, in humans there are good and bad sides and both sides will help someone to find a way out of the problem at hand. Applying artistically with wood and with an asymmetrical arrangement is a medium for expressing the worker's expression symbolized in the form of wood and rope. Wood is strong and can hurt us when we are not careful. Therefore, the authors chose as a medium to reveal symptoms that cause self-injury with wood. Ropes are also used to support this work. The more elastic the rope is tied to the narrower the space for movement. This self-threatening attachment is visualized with the rope. The creation of the work also has no plot and is expressed in symbolic form, using atmosphere music that is made into MIDI is hoped to be able to help and support the desired atmosphere. It is my hope that as the author of this Self Me work it can provide benefits and knowledge to the public, both art and public and the audience about the importance of knowing self-injury from an early age and knowing what the symptoms of self-injury are so that they won't fall into the heavy phase of self-injury. The cultivation of self-love and self-control must be implemented from an early age so that there will be no bullying or similar actions that are detrimental and can lead to self-injury.

\section{References}

Akinlosotu, Ruth Y., Nesreen Alissa, Shari R. Waldstein, Robert A. Creath, George F. Wittenberg, and Kelly P. Westlake. 2021. "Examining the Influence of Mental Stress on Balance Akinlosotu, Ruth Y., Nesreen Alissa, Shari R. Waldstein, Robert A. Creath, George F. Wittenberg, and Kelly P. Westlake. 2021. "Examining the Influence of Mental Stress on Balance Perturbation Responses I." Experimental Gerontology 153 (October): 111495. https://doi.org/10.1016/j.exger.2021.111495.

Augarde, Sophie, and Michelle Rydon-Grange. 2022. "Female Perpetrators of Child Sexual Abuse: A Review of the Clinical and Empirical Literature - A 20-Year Update." Aggression and Violent Behavior 62 (January): 101687. https://doi.org/10.1016/j.avb.2021.101687.

Costa, Marcelo Fernandes, Carlo Martins Gaddi, Vitor Melo Gonsalez, and Fraulein Vidigal de Paula. 2021. "Psychophysical Scaling Method for Measurement of Colors Concept in Children and Adults." Methods in Psychology 5 (December): 100077. https://doi.org/10.1016/j.metip.2021.100077. 
Dharsono Sony Kartika. 2016. Kreasi Artistik: Perjumpaan Tradisi Modern Dalam Paradigma Kekaryaan Seni. Surakarta: Citra Sain.

Douglas, Lindsay N., Austen B. McGuire, Ann M. Manzardo, and Merlin G. Butler. 2016. "High-Resolution Chromosome Ideogram Representation of Recognized Genes for Bipolar Disorder." Gene 586 (1): 13647. https://doi.org/10.1016/j.gene.2016.04.011.

Hamza, Chloe A., and Teena Willoughby. 2018. "A Lab-Based Study Exploring the Associations among Nonsuicidal Self-Injury, Pain, and Emotion among University Students." Psychiatry Research 269 (November): 462-68. https://doi.org/10.1016/j.psychres.2018.08.096.

Kalita, Nazima Rangwala. 2019. "The Art of Re-Interpreting Self: Self Imagery in the Works of Indian Artists." International Journal of Visual and Performing Arts 1 (2): 69-79. https://doi.org/10.31763/viperarts.v1i2.52.

Manurung, Adler Haymans. 2019. Teori Informasi Asimetris. Utilitas. Vol. 1.

O'donovan, Oliver. 2006. The Problem of Self-Love in St. Augustine. Wipf and Stock Publishers.

Pan, Xiong, Lei Wang, Shaobo Zhang, and Ningfang Song. 2019. "Effect of Digital-to-Analog Converter Glitch on the Modulation and Demodulation of a Digital Closed-Loop Fiber-Optic Gyroscope." Optical Fiber Technology 47 (January): 43-50. https://doi.org/10.1016/j.yofte.2018.11.024.

Pfeifer, Eric, Henrike Fiedler, and Marc Wittmann. 2019. "Enhanced Relaxation in Students after Combined Depth Relaxation Music Therapy and Silence in a Natural Setting." The Arts in Psychotherapy 63 (April): 68-76. https://doi.org/10.1016/j.aip.2019.02.006.

Rallis, Ioannis, Nikolaos Doulamis, Anastasios Doulamis, Athanasios Voulodimos, and Vassilios Vescoukis. 2018. "Spatio-Temporal Summarization of Dance Choreographies." Computers \& Graphics 73 (June): 88-101. https://doi.org/10.1016/j.cag.2018.04.003.

Rosdiana, Nursinta Arifiani, Stéphane Dumarçay, Christine Gérardin, Hubert Chapuis, Francisco José Santiago-Medina, Rita Kartika Sari, Wasrin Syafii, et al. 2017. "Characterization of Bark Extractives of Different Industrial Indonesian Wood Species for Potential Valorization." Industrial Crops and Products 108 (December): 121-27. https://doi.org/10.1016/j.indcrop.2017.06.034.

Rusiana, Elfira, and Budi Anna Keliat. 2021. "Relationship between Emotional and Behavioral Problems with Self-Injury in Adolescents." Enfermería Clínica 31 (April): S175-79. https://doi.org/10.1016/j.enfcli.2020.12.017.

Tehrani, Hossein Dabiriyan, and Sara Yamini. 2020. "Dataset of Parenting Practices, Self-Control and AntiSocial Behaviors: Meta-Analytic Structural Equation Modeling.” Data in Brief 32 (October): 106114. https://doi.org/10.1016/j.dib.2020.106114.

Yusuf, Raka, Harni Kusniyati, and Yurike Nuramelia. 2016. "Aplikasi Diagnosis Gangguan Kecemasan Menggunakan Metode Forward Chaining Berbasis Web Dengan PHP Dan MYSQL.” Studia Informatika: Jurnal Sistem Informasi 9 (1). 